\title{
Psychological and Physical Risk Factors for Pressure Pain Hypersensitivity of the Upper Trapezius in Food Service Workers With Nonspecific Neck/shoulder Myofascial Pain
}

\author{
Ui-jae Hwang \\ Yonsei University \\ Oh-yun Kwon ( $\sim$ kwonoy@yonsei.ac.kr) \\ Yonsei University
}

\section{Research Article}

Keywords: myofascial pain, pressure pain hypersensitivity, risk factors, upper trapezius

Posted Date: February 23rd, 2021

DOl: https://doi.org/10.21203/rs.3.rs-224871/v1

License: (c) (1) This work is licensed under a Creative Commons Attribution 4.0 International License. Read Full License 


\section{Abstract}

Objectives: It is unclear which factors increase the risk of developing pressure pain hypersensitivity, a type of neurophysiological hyperexcitability. The present study investigated the relative contributions of physical and psychological factors to pressure pain hypersensitivity of the upper trapezius for each sex.

Methods: In total, 154 individuals with neck/shoulder myofascial pain participated, among 372 food service workers. Participants completed a questionnaire (age, sex, Beck Depression Inventory, and Borg Rating of Perceived Exertion scale) and then were photographed to measure posture. Pressure pain sensitivity, two range of motions (cervical lateral-bending and rotation), and four muscle strengths (serratus anterior, lower trapezius, biceps, and glenohumeral external rotator) were measured by a pressure algometer, iPhone application, and handheld dynamometer. For each sex, forward multivariate logistic regression was used to test our a priori hypothesis among selected variables that a combination of psychosocial and physical factors contributed to the risk for pressure pain hypersensitivity.

Results: In multivariate analyses, lower trapezius strength (odds ratio $=0.94,95 \%$ confidence interval $=$ $0.91-0.97, p=0.001$ ) was the only significant risk factor for pressure pain hypersensitivity in men. Dominant painful ipsilateral cervical rotation range of motion (odds ratio $=0.96,95 \%$ confidence interval $=0.92-0.99, p=0.037$ ) was the only risk factor for pressure pain hypersensitivity in women.

Discussion: Lower trapezius strength and dominant painful ipsilateral cervical rotation range of motion could serve as guidelines for preventing and managing pressure pain hypersensitivity of the upper trapezius in food service workers with nonspecific neck/shoulder myofascial pain.

Trial registration: Research Information Service (CRIS) under the code KCT0002810 (granted on 20/04/2018) and the registration timing was retrospective.

\section{Background}

Food service workers (FWs), such as cooks and restaurant employees, are at high risk for musculoskeletal pain because of the high strain related to serving, preparing raw materials, washing dishes, and cooking [1-3]. A high prevalence of musculoskeletal pain in FWs has been reported. Among 905 individuals in two previous studies, the neck (54.3\%) and shoulders (57.9\%) were more involved than other body regions $(22.3-52.75 \%)[4,5]$. A Norwegian study found that $80 \%$ of hotel FWs reported lifelong musculoskeletal pain, including $42.4 \%$ with neck/shoulder pain [6].

Myofascial pain (MP) is one of the most common causes of musculoskeletal pain [7]. The origin of MP is located at myofascial trigger points, which are hyperirritable regions of tenderness in the taut bands of skeletal muscles [8] that become painful when stimulated (e.g., via compression or other mechanical stimulations) and can contribute to the generation of pain, motor dysfunction, and autonomic responses [8-10]. Among postural muscles, the upper trapezius muscle (UT) is most affected by MP $[7,11,12]$. 
Tenderness over muscles is a common clinical finding in painful conditions of presumed muscular origin $[13,14]$. Pressure pain sensitivity (PPS) is a quantitative sensory test for assessing pain sensitivity in deep tissues [15]. This neurophysiological test may be suitable to measure PPS and tissue tenderness because these conditions are believed to reduce the test values [15].

Although the pathophysiologic mechanism of MP has not been identified, it may involve central sensitization (hyperresponsiveness and hyperexcitability of the central nervous system) [16, 17]. However, it is unclear which factors increase the risk of developing pressure pain hypersensitivity (PPH) in terms of neurophysiological hyperresponsiveness and hyperexcitability. Suggested factors include individual factors (e.g., sex) [18], physical factors (e.g., posture) [19], and psychosocial factors (e.g., depression and stress) [20]. Previous studies have investigated the influences of individual factors on PPS. Thus, there is a need to investigate the combined influences of multiple factors on the risk for PPS.

Physical risk factors are useful and potentially could be modified with interventions such as exercise [21]. Conversely, individual characteristics (e.g., sex and age) cannot be modified. To determine a specific management approach for neck/shoulder pain, Donatelli proposed examination of the following aspects: cervical and shoulder posture, muscle length, rotator cuff muscle strength, and scapular rotator strength [22]. Psychological, biological, and social domains could explain differences in pain severity and perception between men and women with MP $[18,23]$. Concerning sex differences in pain outcomes, PPS has demonstrated the greatest effect size [24] and women are more sensitive to pressure pain than men [25]. Because of sex differences in pain perception and PPS, as well as differences in food service tasks, the relative contributions of physical and psychological risk factors to PPH should be identified for each sex.

Therefore, the present study investigated differences in physical and psychosocial factors between participants according to PPH status for each sex, and the relative contributions of physical and psychological factors to PPH for each sex.

\section{Methods}

\section{Participants}

Participants were recruited through a questionnaire to confirm their experience of neck/shoulder MP as FWs. In total, 154 individuals with neck/shoulder MP participated, from among $372 \mathrm{FWs}$ in a theme park. A flowchart for recruitment of the participants is shown in Fig. 1. Inclusion criteria were non-traumatic neck/shoulder pain, $>6$ months of work in food service, presence of neck/shoulder pain for $\geq 3$ months, and visual analog scale score $>30 \mathrm{~mm}$. Exclusion criteria were shoulder fractures, a prior diagnosis of shoulder instability, a history of surgery in the shoulder, any systemic disease, untreated psychiatric condition, examination suggesting the presence of neurological diseases or internal diseases, hypertension (resting systolic blood pressure $>150 \mathrm{~mm} \mathrm{Hg}$ or diastolic blood pressure $>90 \mathrm{~mm} \mathrm{Hg}$ ), and/or pregnancy. Participant characteristics are shown in Table 1. The experimental protocol was 
established according to the ethical guidelines of the Helsinki Declaration. The study protocol was approved by the Yonsei University Mirae Campus Institutional Review Board (certification number: \#1041849-201603-BM-005-02). Before assessment, the investigator explained the entire experimental procedure and all participants voluntarily provided informed consent.

Table 1

Participant characteristics

\begin{tabular}{|c|c|c|c|c|c|c|}
\hline \multirow[b]{2}{*}{ Age (year) } & \multicolumn{2}{|c|}{ Men $(n=61)$} & \multicolumn{2}{|c|}{ Women $(n=93)$} & \multicolumn{2}{|c|}{ Total $(n=154)$} \\
\hline & 32.05 & $(8.90)$ & 26.15 & $(7.11)$ & 28.49 & $(8.36)$ \\
\hline Height $(\mathrm{cm})$ & 173.82 & $(5.40)$ & 163.57 & $(6.06)$ & 167.63 & $(7.67)$ \\
\hline Weight $(\mathrm{kg})$ & 73.00 & $(8.44)$ & 56.32 & $(7.75)$ & 62.93 & $(11.45)$ \\
\hline Body mass index $\left(\mathrm{kg} / \mathrm{m}^{2}\right)$ & 24.18 & $(2.79)$ & 20.93 & $(2.08)$ & 22.22 & $(2.87)$ \\
\hline Work duration (month) & 62.00 & $(70.16)$ & 41.72 & $(59.49)$ & 50.30 & $(64.80)$ \\
\hline Pain dominant side & Rt: 30 & Lt: 31 & Rt: 46 & Lt: 47 & Rt:76 & Lt:78 \\
\hline Pressure pain hypersensitivity & $47 / 61$ & & $69 / 93$ & & $116 / 154$ & \\
\hline Visual analog scale & 54.02 & $(23.09)$ & 53.99 & $(19.12)$ & 54.00 & $(20.71)$ \\
\hline
\end{tabular}

\section{Outcome measurements}

PPS

PPS was measured with the participant seated upright using a pressure algometer (FPK 60, Wagner Instruments, Inc., Greenwich, CT, USA) with a $1 \mathrm{~cm}$ diameter rubber tip attached to a strain gauge that displayed values in $\mathrm{kg} / \mathrm{cm}^{2}$. The tip was applied to the UT at a standardized location containing the midpoint between $\mathrm{C} 7$ and the acromion process, in the dominant painful side (intraclass correlation coefficient of inter-rater reliability: 0.91) [26, 27]. PPS was defined as the lowest pressure at which the sensation of pressure turned to slight pain or discomfort $[18,26,27]$. The mean value of three trials was calculated and used for the main analyses. A 1 min resting period was allowed between each recording. Both the participant and examiner were blind to force readings during the assessment. A standard metronome was also used to control the rate of increase in pressure. Men with pressure pain sensitivity < $2.9 \mathrm{~kg} / \mathrm{cm}^{2}$ in the UT and women with pressure pain sensitivity $<2.0 \mathrm{~kg} / \mathrm{cm}^{2}$ in the UT were presumed to have PPH [28].

\section{Psychological domain}

The Beck Depression Inventory (BDI) is widely used to measure depression. The BDI consists of 21 items based on symptoms and attitudes that Beck considered common among patients with depression, but 
not among non-depressed individuals [29]. Statements were ranked to indicate the range of depression severity from neutral to maximal.

\section{Physical domains}

Exertion of work intensity was measured using the Borg Rating of Perceived Exertion (BRPE) scale. Participants were asked to self-rate their exertion of work intensity on a scale between 6 and 20 [30].

For cervical range of motion (ROM), the dominant painful contralateral cervical side-bending and dominant painful ipsilateral cervical rotation ROM were measured using an iPhone with Clinometer and Compass applications [31]. Using a belt strap, participants were blocked from performing trunk and shoulder movements during measurements of cervical-lateral bending and rotation movement. The measurements of cervical ROM were made for the total range (i.e., difference between initial and final measures). The mean value of three trials was calculated and used for the main analyses.

For muscle strength, serratus anterior (SA), lower trapezius (LT), biceps and glenohumeral external rotator (GHER) strengths were measured using a handheld dynamometer (JTECH Medical, Salt Lake City, UT, USA) in the dominant painful side. The unit of measurement was a Newton $(\mathrm{N})$ generated by isometric contraction. Muscle strength values were normalized according to participant body weight. The mean value of three trials was calculated and used for analyses. SA strength was measured in scapular protraction and the shoulder was flexed to $125^{\circ}$. Participants were instructed to hold the upper extremity position while the examiner provided a downward force with the handheld dynamometer immediately over the distal humerus. In the prone position, LT strength was measured with the upper extremity diagonally overhead, in line with the LT fibers. The handheld dynamometer was applied to the distal onethird of the participant's radial forearm, and force toward the floor was applied by the examiner. Biceps strength was measured with participants in the sitting position with their elbow flexed to $90^{\circ}$. The handheld dynamometer force sensor was applied to the distal one-third of the participant's forearm, and force toward the floor was applied by the examiner. GHER was measured in the side-lying position with the shoulder flexed and internally rotated to $90^{\circ}$, and the elbow flexed to $90^{\circ}$. Then the dynamometer was applied to the distal one-third of the participant's radial forearm, and force toward the floor was applied by the examiner.

For posture analyses, forward head posture, rounded shoulder angle, shoulder slope angle, and scapular downward rotation ratio were measured using kinematic analyses of photographs using Image J software (National Institutes of Health, Bethesda, MD, USA). Forward head posture was quantified by the craniovertebral angle (angle between the horizontal line passing through $\mathrm{C} 7$ and a line extending from the tragus of the ear to $\mathrm{C7}$ ). The rounded shoulder angle was quantified using the angle ( $\theta$ ) between two lines (from a horizontal line in the medial roots of the scapula to the acromion, and from the root of the scapula to the acromion). The angle $\theta$, composed of the two distances, is one apex of a right-angled triangle. Therefore, $90-\theta$ was defined as the rounded shoulder angle. Shoulder slope angle was quantified by the angle between two lines (a horizontal line with the acromion and a line between the spinous process of the seventh cervical vertebrae and acromion). Scapular downward rotation ratio was 
quantified by the ratio between two lines (a vertical line from the center to the root of the scapula, and a vertical line from the center to the scapular inferior angle).

\section{Procedures}

The present study was performed from March 2016 to November 2016. Participants were assessed at the work conditioning center in a theme park. Variables were measured in the following order: psychological and physical domains (posture, ROM, and strength). Participants were asked to complete a questionnaire (age, sex, BDI, and BRPE scale) and then were photographed to measure posture. PPS, two ROMs (cervical lateral-bending and rotation), and four muscle strengths (SA, LT, biceps, and GHER) were measured in that order.

\section{Statistical Analyses}

The Kolmogorov-Smirnov Z-test was used to assess the assumption of distribution normality. Demographic characteristics are shown as means. Independent t-tests were used to compare psychological and physical domains between participants with PPH and participants without PPH, and to identify significant predictors for cut-off in each sex, because of sex differences in demographic and clinical features. Variables with significant differences between participants according to PPH status in men and women were selected. For each sex, variables associated with PPH were selected from univariate analyses. Finally, for each sex, forward multivariate logistic regression was used to test our a priori hypothesis among selected variables that a combination of psychosocial and physical factors contributed to the risk for $\mathrm{PPH}$. The analyses were adjusted for previously established covariates of age and body mass index. Goodness-of-fit was calculated using the Hosmer-Lemeshow test. Statistical analyses were conducted using SPSS Statistics (ver. 18.0; IBM Corp., Armonk, NY, USA) and the significance level was set at $p<0.05$.

\section{Results}

\section{Comparisons of psychological and physical domains in men according to PPH status}

Table 2 shows comparisons of psychological and physical domains between men with PPH and men without PPH. There were no significant differences in BDI, BRPE scale, forward head posture, rounded shoulder angle, shoulder slope angle, or scapular downward rotation ratio between men with PPH and men without PPH. For cervical ROM, the dominant painful contralateral cervical side-bending $(p=0.02)$ and dominant painful ipsilateral cervical rotation ROM $(p=0.01)$ were significantly greater in men without PPH than in men with PPH. For muscle strengths, SA $(p=0.005)$, LT $(p=0.002)$, biceps $(p<0.001)$, and GHER strength $(p=0.001)$ were significantly greater in men without PPH than in men with PPH. 
Table 2

Comparisons of psychological and physical domains in men according to pressure pain hypersensitivity status ( $\mathrm{n}=-\mathrm{PPH}: 14,+\mathrm{PPH}: 47)$

\begin{tabular}{|c|c|c|c|c|c|c|c|}
\hline Variables & Group & Mean $(\xi$ & & $\mathbf{p}$ & $95 \% \mathrm{C}$ & & \\
\hline Pressure pain threshold & $\begin{array}{l}- \\
\mathrm{PPH}^{\mathrm{a}}\end{array}$ & 3.03 & $(0.19)$ & $0.000^{*}$ & 1.03 & - & 1.31 \\
\hline & $+\mathrm{PPH}$ & 1.86 & $(0.33)$ & & & & \\
\hline Beck Depression Inventory & $-\mathrm{PPH}$ & 25.64 & $(3.25)$ & 0.988 & -2.35 & - & 2.32 \\
\hline & $+\mathrm{PPH}$ & 25.66 & $(5.17)$ & & & & \\
\hline Borg Rating of Perceived Exertion & $-\mathrm{PPH}$ & 13.50 & $(2.21)$ & 0.938 & -1.47 & - & 1.36 \\
\hline & $+\mathrm{PPH}$ & 13.55 & $(2.33)$ & & & & \\
\hline Cervical side-bending $\operatorname{ROM}^{\mathrm{b}}\left({ }^{\circ}\right)$ & $-\mathrm{PPH}$ & 54.68 & $(8.07)$ & $0.007^{*}$ & 2.32 & - & 13.46 \\
\hline & $+\mathrm{PPH}$ & 46.79 & $(11.46)$ & & & & \\
\hline Cervical rotation $\mathrm{ROM}\left({ }^{\circ}\right)$ & $-\mathrm{PPH}$ & 72.18 & $(7.01)$ & 0.058 & -.26 & - & 14.94 \\
\hline & $+\mathrm{PPH}$ & 64.84 & $(13.63)$ & & & & \\
\hline Serratus anterior strength & $-\mathrm{PPH}$ & 242.06 & $(57.65)$ & $0.003^{*}$ & 22.66 & - & 99.43 \\
\hline (normalize:\%) & $+\mathrm{PPH}$ & 181.01 & (72.53) & & & & \\
\hline Lower trapezius strength & $-\mathrm{PPH}$ & 57.81 & $(24.95)$ & $0.000^{*}$ & 15.19 & - & 37.21 \\
\hline (normalize:\%) & $+\mathrm{PPH}$ & 31.61 & $(15.58)$ & & & & \\
\hline Biceps strength & $-\mathrm{PPH}$ & 362.99 & $(73.88)$ & $0.000^{*}$ & 62.66 & - & 171.59 \\
\hline (normalize:\%) & $+\mathrm{PPH}$ & 245.86 & $(93.32)$ & & & & \\
\hline GHER $^{\mathrm{C}}$ strength & $-\mathrm{PPH}$ & 76.32 & $(26.68)$ & $0.005^{*}$ & 8.26 & - & 41.38 \\
\hline (normalize:\%) & $+\mathrm{PPH}$ & 51.50 & $(23.78)$ & & & & \\
\hline Rounded shoulder angle $\left({ }^{\circ}\right)$ & $-\mathrm{PPH}$ & 36.56 & $(4.59)$ & 0.286 & -4.50 & - & 1.39 \\
\hline & $+\mathrm{PPH}$ & 38.11 & $(4.92)$ & & & & \\
\hline Froward head posture $\left(^{\circ}\right)$ & $-\mathrm{PPH}$ & 58.77 & $(11.95)$ & 0.233 & -3.00 & - & 11.57 \\
\hline & $+\mathrm{PPH}$ & 54.49 & $(9.23)$ & & & & \\
\hline Shoulder slope angle $\left(^{\circ}\right)$ & $-\mathrm{PPH}$ & 18.46 & (2.09 & 0.939 & -1.39 & - & 1.50 \\
\hline & $+\mathrm{PPH}$ & 18.40 & (2.96) & & & & \\
\hline
\end{tabular}

${ }^{a} \mathrm{PPH}$, pressure pain hypersensitivity; ${ }^{\mathrm{b}} \mathrm{ROM}$, range of motion; ${ }^{\mathrm{c}} \mathrm{GHER}$, glenohumeral external rotator; ${ }^{*} \mathrm{p}$ $<0.05$ 


\begin{tabular}{|c|c|c|c|c|c|c|c|}
\hline Variables & Group & \multicolumn{2}{|c|}{ Mean (SD) } & \multirow{3}{*}{$\begin{array}{l}\mathbf{p} \\
0.526\end{array}$} & \multicolumn{3}{|c|}{$95 \% \mathrm{Cl}$} \\
\hline \multirow{2}{*}{ Scapular downward rotation ratio } & $-\mathrm{PPH}$ & 0.90 & $(0.15)$ & & -0.07 & - & 0.13 \\
\hline & $+\mathrm{PPH}$ & 0.87 & $(0.15)$ & & & & \\
\hline
\end{tabular}

\section{Comparisons of psychological and physical domains in women according to PPH status}

Table 3 shows comparisons of psychological and physical domains between women with PPH and women without PPH. Most variables were not significantly different, but dominant painful ipsilateral cervical rotation ROM $(p=0.033)$ was significantly greater in women without PPH than in women with $\mathrm{PPH}$. 
Table 3

Comparisons of psychological and physical domains in women according to pressure pain hypersensitivity status ( $\mathrm{N}=-\mathrm{PPH}: 24,+\mathrm{PPH}: 69$ )

\begin{tabular}{|c|c|c|c|c|c|c|c|}
\hline Variables & Group & Mean ( & & p & $95 \% \mathrm{Cl}$ & & \\
\hline Pressure pain threshold & - & 2.36 & $(0.38)$ & $0.000^{*}$ & 0.64 & - & 0.90 \\
\hline$\left(\mathrm{kg} / \mathrm{cm}^{2}\right)$ & मrत & & & & & & \\
\hline & $+\mathrm{PPH}$ & 1.60 & $(0.23)$ & & & & \\
\hline Beck Depression Inventory & $-\mathrm{PPH}$ & 31.21 & $(5.91)$ & 0.666 & -2.24 & - & 3.47 \\
\hline & $+\mathrm{PPH}$ & 30.59 & $(6.09)$ & & & & \\
\hline Borg Rating of Perceived Exertion & $-\mathrm{PPH}$ & 13.29 & $(2.40)$ & 0.432 & -1.59 & - & 0.69 \\
\hline & $+\mathrm{PPH}$ & 13.74 & $(2.31)$ & & & & \\
\hline Cervical side-bending $\operatorname{ROM}^{\mathrm{b}}\left({ }^{\circ}\right)$ & $-\mathrm{PPH}$ & 50.38 & $(7.42)$ & 0.328 & -2.47 & - & 7.30 \\
\hline & $+\mathrm{PPH}$ & 47.96 & $(11.20)$ & & & & \\
\hline Cervical rotation ROM $\left(^{\circ}\right)$ & $-\mathrm{PPH}$ & 69.71 & $(9.52)$ & $0.019^{\star}$ & 1.02 & - & 10.78 \\
\hline & $+\mathrm{PPH}$ & 63.81 & $(12.13)$ & & & & \\
\hline Serratus anterior strength & $-\mathrm{PPH}$ & 176.17 & $(50.09)$ & 0.500 & -16.20 & - & 32.71 \\
\hline (normalize: \%) & $+\mathrm{PPH}$ & 167.91 & $(54.17)$ & & & & \\
\hline Lower trapezius strength & $-\mathrm{PPH}$ & 31.51 & $(11.39)$ & 0.349 & -2.82 & - & 7.79 \\
\hline (normalize: \%) & $+\mathrm{PPH}$ & 29.03 & $(10.00)$ & & & & \\
\hline Biceps strength & $-\mathrm{PPH}$ & 212.91 & $(58.75)$ & 0.088 & -3.72 & - & 51.24 \\
\hline (normalize: \%) & $+\mathrm{PPH}$ & 189.15 & $(52.51)$ & & & & \\
\hline GHER $^{c}$ strength & $-\mathrm{PPH}$ & 49.29 & $(21.55)$ & 0.995 & -8.00 & - & 8.05 \\
\hline (normalize: \%) & $+\mathrm{PPH}$ & 49.26 & $(15.23)$ & & & & \\
\hline Rounded shoulder angle $\left(^{\circ}\right)$ & $-\mathrm{PPH}$ & 37.62 & $(6.78)$ & 0.363 & -1.74 & - & 4.63 \\
\hline & $+\mathrm{PPH}$ & 36.17 & $(6.21)$ & & & & \\
\hline Froward head posture $\left(^{\circ}\right)$ & $-\mathrm{PPH}$ & 51.87 & $(9.12)$ & 0.083 & -8.82 & - & 0.56 \\
\hline & $+\mathrm{PPH}$ & 56.00 & $(11.75)$ & & & & \\
\hline Shoulder slope angle $\left(^{\circ}\right)$ & $-\mathrm{PPH}$ & 16.43 & $(3.95)$ & 0.065 & -0.11 & - & 3.64 \\
\hline & $+\mathrm{PPH}$ & 14.67 & $(3.81)$ & & & & \\
\hline
\end{tabular}




\begin{tabular}{|c|c|c|c|c|c|c|c|}
\hline \multirow{2}{*}{$\begin{array}{l}\text { Variables } \\
\text { Scapular downward rotation ratio }\end{array}$} & \multirow{2}{*}{$\begin{array}{l}\text { Group } \\
-\mathrm{PPH}\end{array}$} & \multicolumn{2}{|c|}{ Mean (SD) } & \multirow{2}{*}{$\begin{array}{l}\mathbf{p} \\
0.726\end{array}$} & \multicolumn{3}{|c|}{$95 \% \mathrm{Cl}$} \\
\hline & & 0.87 & $(0.15)$ & & -0.08 & - & 0.06 \\
\hline & $+\mathrm{PPH}$ & 0.88 & $(0.14)$ & & & & \\
\hline
\end{tabular}

\section{Multivariate prediction model for PPH of UT in men and women}

By comparison of psychological and physical domains between participants with PPH and participants without $\mathrm{PPH}$, the following variables were selected: dominant painful contralateral cervical side-bending, dominant painful ipsilateral cervical rotation ROM, SA, LT, biceps, and GHER strength. The results of univariate analyses of predictors of PPH of UT in men and women are shown in Table 4 and Supplemental Digital Content 1. In univariate analyses, dominant painful contralateral cervical sidebending (odds ratio $(O R)=0.93,95 \%$ confidence interval $(\mathrm{Cl})=0.87-0.99), \mathrm{SA}(\mathrm{OR}=0.99,95 \% \mathrm{Cl}=0.98-$ 1.00), $\mathrm{LT}(\mathrm{OR}=0.94,95 \% \mathrm{Cl}=0.91-0.97)$, biceps $(\mathrm{OR}=0.98,95 \% \mathrm{Cl}=0.96-0.99)$, and GHER strength (OR $=0.96,95 \% \mathrm{Cl}=0.94-0.99)$ were significantly associated with $\mathrm{PPH}$ in men. Moreover, only dominant painful ipsilateral cervical rotation $\mathrm{ROM}(\mathrm{OR}=0.96,95 \% \mathrm{Cl}=0.92-1.00)$ was significantly associated with $\mathrm{PPH}$ in women. 
Table 4

Predictors of pressure pain hypersensitivity using selected variables: results from univariate analyses

\begin{tabular}{|c|c|c|c|c|c|c|}
\hline Sex & Variables & p & OR & $95 \%$ & & \\
\hline \multirow[t]{6}{*}{ Male } & Cervical side-bending ROMa & $0.027^{*}$ & 0.93 & 0.87 & - & 0.99 \\
\hline & Cervical rotation ROM & 0.065 & 0.95 & 0.90 & - & 1.00 \\
\hline & Serratus anterior strength & $0.011^{*}$ & 0.99 & 0.98 & - & 1.00 \\
\hline & Lower trapezius strength & $0.001^{*}$ & 0.94 & 0.91 & - & 0.97 \\
\hline & Biceps strength & $0.002^{*}$ & 0.98 & 0.96 & - & 0.99 \\
\hline & GHER $^{\mathrm{b}}$ strength & $0.005^{*}$ & 0.96 & 0.94 & - & 0.99 \\
\hline \multirow[t]{6}{*}{ Female } & Cervical side-bending ROM & 0.325 & 0.98 & 0.93 & - & 1.02 \\
\hline & Cervical rotation ROM & $0.037^{*}$ & 0.96 & 0.92 & - & 1.00 \\
\hline & Serratus anterior strength & 0.510 & 1.00 & 0.99 & - & 1.01 \\
\hline & Lower trapezius strength & 0.313 & 0.98 & 0.94 & - & 1.02 \\
\hline & Biceps strength & 0.072 & 0.99 & 0.98 & - & 1.00 \\
\hline & GHER strength & 0.995 & 1.00 & 0.97 & - & 1.03 \\
\hline
\end{tabular}

The results of adjusted multivariate analyses of predictors of PPH of UT in men and women are shown in Table 5 and Supplemental Digital Content 1. In the adjusted multivariate model, LT strength $(O R=0.94$, $95 \% \mathrm{Cl}=0.91-0.97, \mathrm{p}=0.001$ ) was the only significant risk factor for PPH of the UT in men. In addition, dominant painful ipsilateral cervical rotation $\mathrm{ROM}(\mathrm{OR}=0.96,95 \% \mathrm{Cl}=0.92-0.99, \mathrm{p}=0.037)$ was the only risk factor for PPH of the UT in women. Goodness-of-fit statistics indicated that model fitting was appropriate for each sex-adjusted regression model (men: $p=0.290$, women: $p=0.061$ ).

Table 5

Predictors of pressure pain hypersensitivity using selected variables: results from adjusted multivariate analyses

\begin{tabular}{|lllllll|}
\hline Sex & Variables & $\mathbf{p}$ & OR & $95 \% \mathrm{Cl}$ & \\
\hline Male & Lower trapezius strength & $0.001^{*}$ & 0.94 & 0.91 & - & 0.97 \\
\hline Female & Cervical rotation ROM & & & \\
& & $0.037^{*}$ & 0.96 & 0.92 & - & 1.00 \\
\hline
\end{tabular}




\section{Discussion}

PPS can result from impairments at multiple levels throughout the neuromuscular system [32]. There is increasing evidence that changes in pain processing may enhance sensitivity to noxious stimuli among individuals with chronic pain, compared to pain-free controls $[14,33]$. The present study investigated whether physical and psychological domains were related to PPH of the UT in each sex among FWs with nonspecific neck/shoulder MP, because biological differences have been suggested to cause sex differences in pain perception [34-36]. LT strength and dominant painful ipsilateral cervical rotation ROM were characterized as risk factors for PPH of the UT in male and female FWs with nonspecific neck/shoulder MP in adjusted multivariate analyses. Although our interpretations are limited because of the cross-sectional study design, the LT strength and dominant painful ipsilateral cervical rotation ROM identified in the present study could be useful for establishing guidelines for the prevention and management of PPH in FWs with nonspecific neck/shoulder MP.

Concerning LT strength as risk factor for PPH, scapulothoracic muscle imbalances could be cause of impaired biomechanics, postural adaptations, and neck/shoulder pain [37, 38]. These imbalances may occur when the UT becomes tight and the LT becomes weak [39, 40]. Conversely, LT weakness could result in UT overload because of poor scapular mechanics (e.g., increasing scapular elevation and decreasing scapular upward rotation and posterior tilting) $[37,38]$ and weakly synergistic acceleration of UT overactivation (e.g., involving the SA and LT) [41]. LT strength was significantly different between the ipsilateral (mean \pm standard deviation (SD): $21.8 \pm 10.0 \mathrm{~N}$ ) and contralateral sides (mean \pm SD: $25.7 \pm 11.5$ $\mathrm{N}$ ) in individuals with unilateral neck and shoulder pain [40]. In the current study, LT strength in male FWs with PPH was $31.61 \pm 15.58 \%$ normalized by body weight. Before LT strength was divided by body weight, LT strength was $23.50 \mathrm{~N}$, which was similar to the results of a previous study involving individuals with neck/shoulder pain [40]. However, Shahidi et al. investigated physical risk factors for chronic neck pain [32]. They found that LT strength was not a risk factor, using a multivariate prediction model that involved cervical active ROM, cervical muscle strength and endurance, and scapular muscle strength. Although this explanation is limited by the cross-sectional study design, LT could be linked to PPH of the UT and could potentially be weaker in terms of PPH of the UT. The process may function in an inverse manner.

Cervical mobility as a risk factor for neck/shoulder pain has been suggested in prospective studies of other populations, but the results have been conflicting. Reduced cervical flexion mobility was more likely to cause neck/shoulder pain in laundry workers (risk ratio: 3.1; 95\% Cl: 1.2-8.3) [42] and increased cervical flexion-extension mobility was protective against neck/shoulder pain in office workers (hazard ratio: $0.97 ; 95 \% \mathrm{Cl}: 0.94-0.99$ ) [43]. With respect to dominant painful ipsilateral cervical rotation ROM as a risk factor for $\mathrm{PPH}$, cervical rotation ROM is related to pain intensity in patients with chronic neck/shoulder pain $[44,45]$. Moreover, patients with nonspecific neck/shoulder pain show less cervical rotation ROM, compared to asymptomatic controls $[46,47]$. Reduced extensibility of upper quadrant neural structures evaluated by the median nerve tension test has been related to decreasing UT length [48]. Furthermore, the presence of PPH of the UT was associated with cervical intervertebral joint dysfunctions [49]. Although interpretations are restricted by the cross-sectional study design, dominant 
painful side ipsilateral cervical rotation ROM could be linked to PPH of the UT and could potentially cause shortness involving PPH of the UT, or the process could function in an inverse manner. UT length affects ipsilateral cervical rotation ROM and contralateral cervical side-bending ROM because of the muscle attachment locations [50]. Thus, tenderness or PPH of the UT could affect the restriction of cervical ipsilateral rotation ROM. Conversely, reduced UT length could affect PPH by scapular dyskinesis (e.g., scapular elevation during arm lifting) [50]. UT shortness and scapular dyskinesis could generate reduced activity of the SA and/or LT, as well as enhanced activity of the UT, resulting in UT overactivation [51, 52].

The psychological domain (depressed mood), as measured using the BDI, was not significantly different between FWs with PPH of the UT and FWs without PPH of the UT in both men ( $p=0.988)$ and women ( $p$ $=0.666$ ). This might have been due to limited statistical power resulting from the small sample size in this study. Psychological depressed mood was reportedly associated with an enhanced risk for neck pain in office workers $(\mathrm{OR}=3.36 ; 95 \% \mathrm{Cl}: 1.10-10.31 ; \mathrm{p}=0.03)$ [32] and others [53,54]. Although it is difficult to directly compare our findings with the results of previous studies, a possible reason for exclusion of the psychological domain from the variable selection process was that the psychological domain could more weakly influence PPH among workers with repetitive and high physical load tasks, compared to white-collar office workers. Furthermore, physical domains of cervical and scapular posture were not significantly different between FWs with PPH of the UT and FWs without PPH of the UT in both men and women. Forward head posture $[55,56]$ and scapular posture [19] have been previously associated with neck/shoulder pain. Because cervical and scapular posture are static characteristics, dynamic physical domains could more strongly influence PPH among workers with repetitive and high physical load tasks, rather than static physical domains.

The main limitations of the present study were its small sample size and cross-sectional study design. Furthermore, this study involved a relatively homogeneous sample of FWs. Future studies are necessary to determine whether the risk factors identified in this study can be generalized to other demographic populations and professions. Future studies should also determine whether improvements in LT strength and cervical rotation ROM are effective for reducing PPH among individuals with neck/shoulder MP.

\section{Conclusion}

The present study investigated physical and psychological risk factors for PPH of the UT in each sex among FWs with nonspecific neck/shoulder MP. LT strength and dominant painful ipsilateral cervical rotation ROM were risk factors for PPH of the UT in men and women in adjusted multivariate analyses. Improvements of LT strength and dominant painful ipsilateral cervical rotation ROM may be protective against PPH in FWs with nonspecific neck/shoulder MP.

\section{Abbreviations}

BDI, Beck depression inventory 
BRPE, Borg rating of perceived exertion

$\mathrm{Cl}$, confidence interval

GHER, glenohumeral external rotator

FW, food service worker

$\mathrm{LT}$, lower trapezius

MP, myofascial pain

OR, odds ratio

$\mathrm{PPH}$, pressure pain hypersensitivity

PPS, pressure pain sensitivity

$\mathrm{ROM}$, range of motion

SA, serratus anterior

UT, upper trapezius

\section{Declarations}

\section{Ethic approval and consent to participate}

The experimental protocol was established according to the ethical guidelines of the Helsinki Declaration. The study protocol was approved by the Yonsei University Mirae Campus Institutional Review Board (certification number: \#1041849-201603-BM-005-02). The participants were then asked to sign a written informed consent. The informed consent was made in two identical copies that the participants could retain one.

\section{Consent for publication}

Not applicable.

\section{Availability of data and materials}

The datasets analyzed during the current study are available from the corresponding author on reasonable request.

\section{Competing interest}


The authors declare that they have no potential conflicts of interest with respect to the research, authorship, and publication of this article. The results are presented clearly, honestly, and without fabrication, falsification, or inappropriate data manipulation.

\section{Funding}

Yonsei University Research Fund (grant numbers: 2020-52-0016) provided funding for this study.

\section{Author contributions}

UJH contributes to conceptualization, project administration, writing-original draft, data curation, investigation, methodology and formal analysis in the present study. OYK contributes to conceptualization, funding acquisition, project administration and writing-original draft in the current study. All authors reviewed the manuscript.

\section{Acknowledgments}

We would like to thank all of the participants for their time and commitment to the present study.

\section{References}

1. Chyuan JYA, Du CL, Yeh WY, Li C-Y: A cross-sectional study of musculoskeletal disorders in relation to work movement characteristics among hotel foodservice employees in Taiwan. Taiwan Journal of Public Health 2002, 21(2):140-149.

2. Chyuan J: Risk factors associated with work-related musculoskeletal discomfort among commissary foodservice workers. Taiwan J Public Health 2005, 24:154-161.

3. Haukka E, Leino-Arjas P, Solovieva S, Ranta R, Viikari-Juntura E, Riihimäki H: Co-occurrence of musculoskeletal pain among female kitchen workers. International archives of occupational and environmental health 2006, 80(2):141-148.

4. Chyuan J-YA, Du C-L, Yeh W-Y, Li C-Y: Musculoskeletal disorders in hotel restaurant workers. Occupational Medicine 2004, 54(1):55-57.

5. Shiue HS, Lu CW, Chen CJ, Shih TS, Wu SC, Yang CY, Yang YH, Wu TN: Musculoskeletal disorder among 52,261 Chinese restaurant cooks cohort: result from the National Health Insurance Data. Journal of occupational health 2008, 50(2):163-168.

6. Ihlebæk C, Eriksen HR, Ursin H: Prevalence of subjective health complaints (SHC) in Norway. Scandinavian journal of public health 2002, 30(1):20-29.

7. Meleger AL, Krivickas LS: Neck and back pain: musculoskeletal disorders. Neurologic clinics 2007, 25(2):419-438.

8. Simons DG: Review of enigmatic MTrPs as a common cause of enigmatic musculoskeletal pain and dysfunction. Journal of electromyography and kinesiology 2004, 14(1):95-107. 
9. Gerwin RD, Dommerholt J, Shah JP: An expansion of Simons' integrated hypothesis of trigger point formation. Current pain and headache reports 2004, 8(6):468-475.

10. Ge H-Y, Arendt-Nielsen L: Latent myofascial trigger points. Current pain and headache reports 2011, 15(5):386-392.

11. Luime J, Koes B, Hendriksen I, Burdorf A, Verhagen A, Miedema H, Verhaar J: Prevalence and incidence of shoulder pain in the general population; a systematic review. Scandinavian journal of rheumatology 2004, 33(2):73-81.

12. Chang C-W, Chang K-Y, Chen Y-R, Kuo P-L: Electrophysiologic evidence of spinal accessory neuropathy in patients with cervical myofascial pain syndrome. Archives of physical medicine and rehabilitation 2011, 92(6):935-940.

13. Persson A, Brogardh C, Sjolund B: Tender or not tender: test-retest repeatability of pressure pain thresholds in the trapezius and deltoid muscles of healthy women. Journal of Rehabilitation Medicine 2004, 36(1):17-27.

14. Sjörs A, Larsson B, Persson AL, Gerdle B: An increased response to experimental muscle pain is related to psychological status in women with chronic non-traumatic neck-shoulder pain. $B M C$ musculoskeletal disorders 2011, 12(1):230.

15. Graven-Nielsen T, Arendt-Nielsen L: Assessment of mechanisms in localized and widespread musculoskeletal pain. Nature Reviews Rheumatology 2010, 6(10):599-606.

16. Desmeules JA, Cedraschi C, Rapiti E, Baumgartner E, Finckh A, Cohen P, Dayer P, Vischer T: Neurophysiologic evidence for a central sensitization in patients with fibromyalgia. Arthritis \& Rheumatism 2003, 48(5):1420-1429.

17. Montoya P, Pauli P, Batra A, Wiedemann G: Altered processing of pain-related information in patients with fibromyalgia. European Journal of Pain 2005, 9(3):293-303.

18. Castro-Sanchez AM, Mataran-Penarrocha GA, Lopez-Rodriguez MM, Lara-Palomo IC, Arendt-Nielsen L, Fernández-de-las-Peñas C: Gender differences in pain severity, disability, depression, and widespread pressure pain sensitivity in patients with fibromyalgia syndrome without comorbid conditions. Pain medicine 2012, 13(12):1639-1647.

19. Azevedo DC, de Lima Pires T, de Souza Andrade F, McDonnell MK: Influence of scapular position on the pressure pain threshold of the upper trapezius muscle region. European Journal of pain 2008, 12(2):226-232.

20. Vedolin G, Lobato V, Conti P, Lauris J: The impact of stress and anxiety on the pressure pain threshold of myofascial pain patients. Journal of oral rehabilitation 2009, 36(5):313-321.

21. Jull G, Trott P, Potter H, Zito G, Niere K, Shirley D, Emberson J, Marschner I, Richardson C: A randomized controlled trial of exercise and manipulative therapy for cervicogenic headache. Spine 2002, 27(17):1835-1843.

22. Donatelli RA: Physical Therapy of the Shoulder-E-Book: Elsevier Health Sciences; 2011.

23. Yunus MB: Gender differences in fibromyalgia and other related syndromes. The journal of genderspecific medicine: JGSM: the official journal of the Partnership for Women's Health at Columbia 
2002, 5(2):42-47.

24. Riley III JL, Robinson ME, Wise EA, Myers CD, Fillingim RB: Sex differences in the perception of noxious experimental stimuli: a meta-analysis. Pain 1998, 74(2-3):181-187.

25. Chesterton LS, Barlas P, Foster NE, Baxter GD, Wright CC: Gender differences in pressure pain threshold in healthy humans. Pain 2003, 101(3):259-266.

26. Chesterton LS, Sim J, Wright CC, Foster NE: Interrater reliability of algometry in measuring pressure pain thresholds in healthy humans, using multiple raters. The Clinical journal of pain 2007, 23(9):760-766.

27. Jones $\mathrm{DH}$, Kilgour RD, Comtois AS: Test-retest reliability of pressure pain threshold measurements of the upper limb and torso in young healthy women. The Journal of Pain 2007, 8(8):650-656.

28. Lucas KR, Polus $\mathrm{BI}$, Rich PA: Latent myofascial trigger points: their effects on muscle activation and movement efficiency. Journal of Bodywork and Movement Therapies 2004, 8(3):160-166.

29. Beck J, Kohout F, Hunt R: Identification of high caries risk adults: attitudes, social factors and diseases. International dental journal 1988, 38(4):231.

30. Williams N: The Borg rating of perceived exertion (RPE) scale. Occupational Medicine 2017, 67(5):404-405.

31. Tousignant-Laflamme Y, Boutin N, Dion AM, Vallée C-A: Reliability and criterion validity of two applications of the iPhone $^{\mathrm{m}}$ to measure cervical range of motion in healthy participants. Journal of neuroengineering and rehabilitation 2013, 10(1):69.

32. Shahidi B, Curran-Everett D, Maluf KS: Psychosocial, physical, and neurophysiological risk factors for chronic neck pain: a prospective inception cohort study. The Journal of pain 2015, 16(12):12881299.

33. Andersen JH, Kaergaard A, Frost P, Thomsen JF, Bonde JP, Fallentin N, Borg V, Mikkelsen S: Physical, psychosocial, and individual risk factors for neck/shoulder pain with pressure tenderness in the muscles among workers performing monotonous, repetitive work. Spine 2002, 27(6):660-667.

34. Bushnell M, Duncan G, Hofbauer R, Ha B, Chen J-I, Carrier B: Pain perception: is there a role for primary somatosensory cortex? Proceedings of the National Academy of Sciences 1999, 96(14):7705-7709.

35. Craft RM: Modulation of pain by estrogens. Pain 2007, 132:S3-S12.

36. Greenspan JD, Craft RM, LeResche L, Arendt-Nielsen L, Berkley KJ, Fillingim RB, Gold MS, Holdcroft A, Lautenbacher S, Mayer EA: Studying sex and gender differences in pain and analgesia: a consensus report. Pain 2007, 132:S26-S45.

37. Cools A, Witvrouw E, Declercq G, Vanderstraeten G, Cambier D: Evaluation of isokinetic force production and associated muscle activity in the scapular rotators during a protraction-retraction movement in overhead athletes with impingement symptoms. British journal of sports medicine 2004, 38(1):64-68. 
38. Cools AM, Dewitte V, Lanszweert F, Notebaert D, Roets A, Soetens B, Cagnie B, Witvrouw EE: Rehabilitation of scapular muscle balance: which exercises to prescribe? The American journal of sports medicine 2007, 35(10):1744-1751.

39. Janda V: Muscles and motor control in cervicogenic disorders Teoksessa Grant, R (toim) Physical Therapy of the Cervical and Thoracic Spine. In.: Amsterdam: Elsevier Science; 2002: 182-199.

40. Petersen SM, Wyatt SN: Lower trapezius muscle strength in individuals with unilateral neck pain. journal of orthopaedic \& sports physical therapy 2011, 41(4):260-265.

41. Arlotta M, LoVasco G, McLean L: Selective recruitment of the lower fibers of the trapezius muscle. Journal of Electromyography and Kinesiology 2011, 21(3):403-410.

42. Norlander S, Gustavsson B, Lindell J, Nordgren B: Reduced mobility in the cervico-thoracic motion segment-a risk factor for musculoskeletal neck-shoulder pain: a two-year prospective follow-up study. Scandinavian journal of rehabilitation medicine 1997, 29(3):167-174.

43. Hush JM, Michaleff Z, Maher CG, Refshauge K: Individual, physical and psychological risk factors for neck pain in Australian office workers: a 1-year longitudinal study. European spine journa/2009, 18(10):1532-1540.

44. Treleaven J, Chen X, Bahat HS: Factors associated with cervical kinematic impairments in patients with neck pain. Manual therapy 2016, 22:109-115.

45. Piña-Pozo F, Heredia-Rizo AM, Madeleine P, Escobio-Prieto I, Luque-Carrasco A, Oliva-Pascual-Vaca Á: Local and Widespread Pressure Pain Hyperalgesia Is Not Side Specific in Females with Unilateral Neck Pain that Can Be Reproduced during Passive Neck Rotation. Journal of clinical medicine 2019, 8(8):1246.

46. Lascurain-Aguirrebeña I, Newham DJ, Casado-Zumeta X, Lertxundi A, Critchley DJ: Immediate effects of cervical mobilisations on global perceived effect, movement associated pain and neck kinematics in patients with non-specific neck pain. A double blind placebo randomised controlled trial. Musculoskeletal Science and Practice 2018, 38:83-90.

47. Alsultan F, Cescon C, De Nunzio AM, Barbero M, Heneghan NR, Rushton A, Falla D: Variability of the helical axis during active cervical movements in people with chronic neck pain. Clinical Biomechanics 2019, 62:50-57.

48. Edgar D, Jull G, Sutton S: The relationship between upper trapezius muscle length and upper quadrant neural tissue extensibility. Australian Journal of Physiotherapy 1994, 40(2):99-103.

49. de las Peñas CF, Carnero JF, Page JM: Musculoskeletal Disorders in Mechanical Neck Pain: Myofascial Trigger Points versus Cervical Joint Dysfunction-A Clinical Study. Journal of Musculoskeletal Pain 2005, 13(1):27-35.

50. Yeşilyaprak SS, Yüksel E, Kalkan S: Influence of pectoralis minor and upper trapezius lengths on observable scapular dyskinesis. Physical Therapy in Sport 2016, 19:7-13.

51. Falla D, Farina D, Graven-Nielsen T: Experimental muscle pain results in reorganization of coordination among trapezius muscle subdivisions during repetitive shoulder flexion. Experimental brain research 2007, 178(3):385-393. 
52. Kibler WB, Ludewig PM, McClure PW, Michener LA, Bak K, Sciascia AD: Clinical implications of scapular dyskinesis in shoulder injury: the 2013 consensus statement from the 'Scapular Summit'. British journal of sports medicine 2013, 47(14):877-885.

53. Linton SJ: A review of psychological risk factors in back and neck pain. Spine 2000, 25(9):11481156.

54. Carroll LJ, Cassidy JD, Côté P: Depression as a risk factor for onset of an episode of troublesome neck and low back pain. Pain 2004, 107(1-2):134-139.

55. Cagnie B, Danneels L, Van Tiggelen D, De Loose V, Cambier D: Individual and work related risk factors for neck pain among office workers: a cross sectional study. European Spine Journal 2007, 16(5):679-686.

56. Kocur P, Wilski M, Lewandowski J, Łochyński D: Female office workers with moderate neck pain have increased anterior positioning of the cervical spine and stiffness of upper trapezius myofascial tissue in sitting posture. Pm\&r 2019, 11(5):476-482.

\section{Figures}


Questionnaire survey for recruitment

of food service workers $(\mathrm{N}=372)$

[Permanent position $(\mathrm{N}=125)+$ Temporary position $(\mathrm{N}=247)$ ]

\section{Selected food service workers who experience neck/shoulder pain through questionnaire survey $(\mathrm{N}=255)$}

[Permanent position $(\mathrm{N}=97)+$ Temporary position $(\mathrm{N}=158)]$

\begin{tabular}{l}
$\begin{array}{l}\text { Assessed for eligibility }(\mathrm{N}=255) \\
\text { [Permanent position }(\mathrm{N}=97)+\text { Temporary position }(\mathrm{N}=158)]\end{array}$ \\
\hline
\end{tabular}

Participants with neck/shoulder myofascial pain $(\mathrm{N}=154)$

[Permanent position $(\mathrm{N}=60)+$ Temporary position $(\mathrm{N}=94)]$
Excluded participants $(\mathrm{N}=101)$

- Hypertension $(\mathrm{N}=61)$

- History of surgery $(\mathrm{N}=34)$

- Shoulder fracture $(\mathrm{N}=3)$

- Shoulder instability $(\mathrm{N}=3)$

\section{Figure 1}

Flow diagram of participant selection.

\section{Supplementary Files}

This is a list of supplementary files associated with this preprint. Click to download.

- Statisticalanalysis.xlsx 